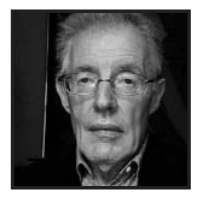

\title{
The Pedagogy of the Imagination
}

\author{
Michael Armstrong, Middlebury College, Vermont
}

\section{ABSTRACT (Press Here for Sound)}

The author takes an essay on the imagination by Italo Calvino as the cue for a reconsideration of the role of imagination in children's thought and action and its educational implications. He emphasizes the value of interpretation, or critical scrutiny, as foremost among a teacher's skills and central to curriculum design, teaching method and educational assessment, demonstrating the quality of children's imaginative work, and how to value it, by means of a close reading of an eight year old's brief meditation on coming to school for the first time.

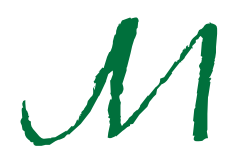

y title is taken from a late essay by the Italian novelist Italo Calvino. Calvino died in 1985, on the eve of his departure for the USA where he was due to deliver the Charles Eliot Norton lectures at Harvard University. He had already written five of the six promised lectures and was planning to complete the sixth on his arrival in Cambridge. The five completed lectures were published posthumously in 1988, under the supervision of Calvino's widow, with the title which Calvino had chosen for the entire series: Six Memos for the Next Millennium (Calvino, 1988). Calvino devotes his lectures to "certain values, qualities, or peculiarities of literature that are very close to my heart" (p. 1):lightness, quickness, exactitude, visibility and multiplicity. The fourth lecture, on visibility, is, in effect, a celebration of the literary imagination and of the role which it plays in Calvino's own work and the work of those writers of the past whom he most admires. It is with this remarkable essay that my argument begins. 
Calvino distinguishes between "two types of imaginative process: the one that starts with the word and arrives at the visual image, and the one that starts with the visual image and arrives at its verbal expression" (p. 83). He further distinguishes between two modes of imaginative thought, "imagination as an instrument of knowledge" and "imagination as participation in the truth of the world" or as "a communication with the world soul" (p. 88). Calvino is in no doubt that his own work starts with the visual image. "When I began to write fantastic stories," he tells us, "I did not yet consider theoretical questions. The only thing I knew was that there was a visual image at the source of all my stories" (p. 88). He defines his creative procedure as follows:

In devising a story, therefore, the first thing that comes to my mind is an image that for some reason strikes me as charged with meaning, even if I cannot formulate this meaning in discursive or conceptual terms. As soon as the image has become sufficiently clear in my mind, I set about developing it into a story; or better yet, it is the images themselves that develop their own implicit potentialities, the story they carry within them. Around each image others come into being, forming a field of analogies, symmetries, confrontations. Into the organisation of this material, which is no longer purely visual but also conceptual, there now enters my deliberate intent to give order and sense to the development of the story; or rather, what I do is try to establish which meanings might be compatible with the overall design I wish to give the story and which meanings are not compatible, always leaving a certain margin of possible alternatives. At the same time, the writing, the verbal product, acquires increasing importance. I would say that from the moment I start putting black on white, what really matters is the written word, first as a search for an equivalent of the visual image, then as a coherent development of the initial stylistic direction. Finally, the written word little by little comes to dominate the field. From now on it will be the writing that guides the story toward the most felicitous verbal expression, and the visual imagination has no choice but to tag along. (p. 89)

Although Calvino is in no doubt about his own creative procedure, he is less decisive in choosing between alternate modes of imaginative thought. In his opening lecture he had described himself as "accustomed to consider literature a search for knowledge" (p. 26), but he is equally aware of the existential quality of imaginative thought, its distinctive mode of being: 
I have always sought out in the imagination a means to attain a knowledge that is outside the individual, outside the subjective. It is right, then for me to declare myself closer to the second position, that of identification with the world soul. (p.91)

Above all, he recognizes in the imagination "a repertory of what is potential, what is hypothetical, of what does not exist and has never existed, and perhaps will never exist but might have existed" (p. 91). He cites the Italian Renaissance philosopher Giordano Bruno who defines the spiritus phantasticus as "a world or a gulf, never saturable, of forms and images," and he concludes:

So, then, I believe that to draw on this gulf or potential multiplicity is indispensable to any form of knowledge. The poet's mind, and at a few decisive moments the mind of the scientist, works according to a process of association of images that is the quickest way to link and to choose between the infinite forms of the possible and the impossible. (p. 91)

Calvino is anxious about the survival of the imagination, and in particular its visual aspect, in the modern age, "bombarded" as we are "by such a quantity of images that we no longer distinguish direct experience from what we have seen for a few seconds on television" (p.92). It is this anxiety which leads him to propose,

some possible pedagogy of the imagination that would accustom us to control our own inner vision without suffocating it or letting it fall, on the other hand, into confused, ephemeral daydreams, but would enable the images to crystallise into a well-defined, memorable, and self-sufficient form, the icastic form ... (p. 92)

But this would be an unusual form of pedagogy, "a kind of pedagogy that we can only exercise upon ourselves, according to methods invented for the occasion and with unpredictable results" (p. 92)

I want now to extend and redirect Calvino's proposal for a pedagogy of the imagination. But first we need to examine the way in which a young child, at the beginning of a writing life, exploits the literary imagination as Calvino describes it.

New Kid is a short meditation written by an eight-year-old boy named Chris, a third grade pupil in one of the public elementary schools in the city of Lawrence, an impoverished old mill town north of Boston. 


\section{New Kid}

It's hard being a new kid you have to stand there holding a blue pencil and having a desk that's blue just like the sea when it's a wack and everyone making fun of you because you have no friends and the teacher analying you like a bird flying around you it's hard being a new kid.

Like many of his classmates, Chris was born in the Dominican Republic. He is a large, quiet, soft-spoken boy, thoughtful, even dreamy. When he reads his work to the rest of his class at the end of the day, he reads shyly but with evident pleasure, smiling as he comes to the end. New Kid was not written in response to any assignment; it was Chris's own choice of subject. He wrote it at a single sitting and although he made a copy later, he changed no more than a single word, replacing the words "not good" by the word "hard" in the final line, a significant choice as we will see. His handwritten copy is faint but clear. The title is large and eye-catching, twice the size of the rest of the text, which begins immediately below and takes up ten lines; the individual words widely spaced, the letters distinct, every letter i surmounted by a tiny circle. Only two words are misspelt: "awake" is written as "a wack" and "analyzing" becomes "analying."There is a full stop after the last word but no further punctuation.

Visibility is the foremost quality of Chris's meditation. It opens with a visual image that is "charged with meaning" in much the same way as Calvino claims for his own work: the image of a forlorn child standing beside a blue desk, clutching a blue pencil. Although Chris told me that he was thinking of his own entry into first grade, his meditation is not strictly autobiographical. Its subject is "you" as the unpunctuated opening makes clear, immediately juxtaposing the word "kid" and the word "you" as if to identify the subject of the meditation with whoever might be reading it: "It's hard being a new kid you have to stand there." "You" stands for writer and reader alike, for anyone who has ever felt the loneliness of the newcomer, forced into a situation that he has in no way chosen for himself: "you have to." It invites us to make the experience our own, whether in memory or in imagination.

Calvino writes of how "it is the images themselves that develop their own implicit potentialities" so that "around each image, others come into being, forming a field of analogies, symmetries, confrontations" (p. 89). Chris's meditation matches this description word for word. The potentiality of its opening image depends upon the colour blue. Among the many meanings of the word blue in The New Shorter Oxford English Dictionary (1993), we find "the colour of sorrow or anguish," "the clear sky, the sea, the desert; the indefinite distance; the unknown," "depressed, low-spirited, dismayed, downcast" (p. 248) The image of the child with the blue pencil by the blue 
desk evokes each of these definitions in turn, almost as if the writer is playing on the meaning of blue, both colour and word. From the local and particular blue of the classroom, the meditation moves to the infinite blue of the sea "when it's a wack." Chris told me that he had in mind the sea in the early morning, adding that when he was in first grade he was often thinking of the sea, though he did not say why. "Awake" suggests activity, energy, renewed life, but the life to come is anything but peaceful or reassuring. The morning sea matches the morning classroom in its allembracing blueness, the blue of the indefinite, the unknown, the downcast, the colour of anguish, a blue that both heralds the day and threatens its promise.

In one of his late essays, the Russian literary theorist Mikhail Bakhtin (1986) describes the exceptional significance of visibility in the work of Goethe in the following terms:

Even the very basis of a philosophical world view can be revealed in a simple and clear visual image. When travelling from Naples to Sicily, Goethe found himself on the open sea for the first time, encircled by the line of the horizon. He said, 'No-one who has never seen himself surrounded on all sides by nothing but the sea can have a true conception of the world and of his own relation to it.' (. p. 28)

The simile of the wakeful sea in New Kid has the same philosophical resonance. Here too the truth of the world is represented in visible form, the child's isolation mirrored in the blueness of the sea. There is a distant echo of The Rime of the Ancient Mariner, even if Chris has never as yet come across Coleridge's (17971798/1978) poem:“Alone, alone, all, all alone, / Alone on a wide wide sea!" (p. 90)

But the child in the classroom is not alone, or rather, his loneliness is despite, or even because of, the crowded presence of his classmates and his teacher. As the text leads us back from the sea to the classroom, the child's isolation is reinforced by the clamour of those around him, his classmates making fun of him and his teacher analyzing him "like a bird flying around you." Under the influence of the image of the sea, the circling bird brings to mind, if not an albatross, then a seagull, screaming as it circles the boat. This time, however, it is not an image that evokes the simile but a word, the word "analyzing." Around this word there hangs another story. I was surprised when I encountered the word in Chris's meditation. It was not a word I would have expected to find him using. But then I caught sight of a notice on the wall of the classroom in which he was working: "Analyze: to look at closely." A day or two later came an announcement on the school's loudspeaker, after the morning pledge of 
allegiance: "our MCAS word of the week is 'analyze'; 'analyze' means to break into parts and look at closely." Two children repeated the definition after the teacher. It seems likely that this is how Chris had first encountered the word. The authors of the Massachusetts Comprehensive Assessment System might be gratified to discover a child so freely making use of their word of the week. But in appropriating the word, Chris has, by means of a new simile, dramatically enlarged its emotional range. The word has lost its impersonal or positive emphasis and acquired the force of a nightmare. In a single flourish of the literary imagination, Chris has bestowed on the word "analyze" a poetical significance far removed from the blandness of the MCAS word list. By making the visual image an equivalent of the word, the reverse of Calvino's declared procedure, the word itself has taken on a revolutionary new life.

In this extraordinary extension of the word's connotation there is a distant echo of some remarks of Leo Tolstoy (1982) on the perils of comprehension exercises such as those which he himself had given to children at the peasant school which he founded on his family estate at Yasnaya Polyana in the 1860s. At the end of a devastating critique of one of his own lessons he writes as follows:

We must give the pupil opportunities to acquire new concepts and words from the general sense of what is said. He will hear or read an incomprehensible word in an incomprehensible sentence once, then again in another sentence, and a new concept will begin dimly to present itself to him, and at length he will, by chance, feel the necessity of using that word, he will use it once, and word and concept become his property. And there are thousands of other paths. But deliberately to present a pupil with new concepts and forms of language is, according to my conviction, as unnecessary and pointless as to teach a child to walk by means of the laws of equilibrium. Any such attempt carries a pupil not nearer to the appointed goal but further away from it, as if a man should wish to help a flower to open out with his crushed hand, should begin to unfold the petals, and crush everything round about. (p. 125)

It is in just such a way that Chris has made the word "analyse" his property and in the process has enlarged the word's significance. It will be hard to think of word or concept in quite the same way again.

The meditation ends with the same six words with which it began. The selfconsciousness of this ending is unmistakable, confirmed, as it is, by Chris's cancellation of the words "not good" in favour of the original "hard." There could be no clearer 
sign of Chris's "deliberate intent to give order and sense to the development of the story." But the argument is not circular. To encounter these words once more is to understand them quite differently; the meditation has reconstructed their meaning, just as the image of the bird reconstructed the meaning of the word "analyze." And now we can see the value that lies in the absence of punctuation throughout the meditation. By binding his central vision so seamlessly to the dogmatic beginning and ending, Chris makes visible his intention to re-create imaginatively the newcomer's experience. "This is how we are to understand the plight of the new kid, now do you see?" the meditation asks us, and to confirm its argument the opening words are repeated, transformed by the vision which they frame. So the parable of the new kid is at the same time a parable of poetic form, of the way in which the written word makes all things new.

Chris's achievement raises the question which Calvino asks of himself: is his mode of imaginative thought best described as an instrument of knowledge or as participation in the truth of the world? The answer is, surely, that it is both. What is it that Chris knows? The experience of being a new kid is common enough in Chris's school. Almost every week there will be a newcomer in his own or a neighbouring class. His meditation brings that experience to imaginative life. It shows us what it means to be the newcomer, the outsider, the other. But the meditation is not evidence of his knowledge so much as its embodiment. In writing it he has come to understand for himself what his words and images make us, his readers, understand. His meditation represents what he knows. And like all imaginative thought his work reconstructs the knowledge which it represents. So the word "analyze" acquires a new shade of meaning, the blue of the morning sea seems more of a threat than a promise, the absence of punctuation becomes a merit rather than a defect.

What, then, of the imagination as participation in the truth of the world? Chris's evocation of the sea is the measure of his participation. It lifts his meditation above the local and particular setting of the small child in the classroom, into the universal experience of loneliness and isolation. I am reminded of a passage from the preface to Henry James's (1934) great novel of childhood, What Maisie Knew, in which James describes his intentions in writing the novel from the standpoint of a perceptive young child."I lose myself, truly," he writes," in appreciation of my theme on noting what she [Maisie] does by her "freshness" for appearances in themselves vulgar and empty enough. They become, as she deals with them, the stuff of poetry and tragedy and art; she has simply to wonder, as I say, about them, and they begin to have meanings, aspects, solidities, connexions - connexions with the "universal" - that they could scarce have hoped for" (p. 147). "Meanings, aspects, solidities, connexions," 
these are the very terms that seem appropriate to the effects of Chris's wonder, as displayed in his meditation. His visual and verbal imagination connects the local with the universal, the incidental with the essential, converting the trivialities of the classroom into poetry and tragedy and art. This is the way in which he communicates with the world soul, as Calvino puts it. It is the quality of mind which W.B. Yeats has in mind, in Among School Children, when he stands in "the long schoolroom," taking note of how "the children's eyes/ In momentary wonder stare upon/A sixty-year-old smiling public man":

I dream of a Ledaean body, bent

Above a sinking fire, a tale that she

Told of a harsh reproof, or trivial event

That changed some childish day to tragedy -

Told, and it seemed that our two natures blent

Into a sphere from youthful sympathy,

Or else, to alter Plato's parable,

Into the yolk and white of the one shell.

Such an achievement, as notable as it is fragile, is no exception. On the contrary, it is characteristic of children's writing, from their earliest attempts to put their thought into written form (Armstrong, 2006). Works such as New Kid represent the early life of the literary imagination, much as Calvino describes it, and demonstrate its vitality from the outset of literacy. The educational value of the imaginative life can scarcely be exaggerated. In as much as children's imaginative work embodies their knowledge and represents their engagement with the truth of the world, it is fundamental to the entire educational process so long as that process is conceived in Calvino's humanistic terms. What works such as New Kid demonstrate is that it is through the exercise of imagination that children learn to participate in culture. The imagination, grounded in play, is the form of thought which determines their cultural practice from infancy onwards. Chris is no stranger to culture nor simply a spectator; he is a maker, a player, a composer, whose works reinvent the world even as they discover it.

The imagination is fundamental to education in a variety of ways. Firstly, imaginative work is both an embodiment of children's knowledge and the means to its advancement. Works build on works as children use their writing or art, their mathematics or science, to put their experience to the test, explore its significance, and represent their growing understanding in an appropriate form. Thinking and making are inextricable in their practice, as New Kid shows us. Secondly, it is imaginative work 
which provides the appropriate context for the development of skill. So it was for Chris when he discovered the word that he could both appropriate and reconfigure in order to capture the new kid's experience, the word "analyze." So it will be later with the use he makes of punctuation, although for the moment he can usefully exploit the very absence of punctuation for dramatic effect, making a virtue of a missing technique. Thirdly, imaginative work sets the terms for the course of instruction, as teachers respond to children's interests, enthusiasms and concerns in ways that match the freshness of the child's wonder to the culture's accumulated knowledge. It is not that children's concerns in themselves determine the curriculum but rather that the curriculum represents a mutual exchange, never fixed, between the child's wonder, the teacher's experience and the subject matter of the various arts, sciences and technologies, that triangular relationship, memorably defined by the philosopher David Hawkins (1974), in one of his educational essays, as the relationship between I, Thou and It. So it might be that the way in which Chris's meditation brought to my mind Coleridge's poem would lead me to introduce Chris to the poem and to explore with him other poems or stories on similar themes. And fourthly, it is the imagination that makes formal education, from kindergarten onwards, a major expression of culture rather than a preparation for it. To examine the writing of a young child like Chris, as he explores the new kid's experience, is to rediscover the meaning of loneliness. His writing challenges us, even as we respond with our own reciprocal challenges.

I want to return now to Calvino's proposal of a pedagogy of the imagination and to ask what such a pedagogy implies within the context of a common education. Calvino's chief concern is over the fate of the visual imagination in what he calls "the civilization of the image," but I propose to broaden the investigation to include the imagination in all its forms: visual, verbal, auditory, and conceptual. According to Calvino, a pedagogy of the imagination is "a kind of pedagogy that we can only exercise upon ourselves." He has in mind, I think, the writer's ultimate responsibility for his own development from one work to the next and the uniqueness of every artist's predicament. His subsequent account of his own early life as a child obsessed by the world of the cartoon image bears out his claim. In the end it is children themselves who determine the progress of their thought from work to work. But teachers are the catalysts of children's imaginative growth and it is with children and their teachers together that I shall be concerned here.

So how do children learn to control and shape their inner vision and, in particular, how do teachers support their students' imaginative growth? I believe that the answer lies in interpretation, the art of observing, describing, responding and connecting, which seems to me foremost among a teacher's skills. By interpretation I 
have in mind the close reading of children's work, whatever form that work may take. Close reading entails an intricate interplay between the observation of work in progress, unprejudiced description of the finished product, explication of the work's meaning, and the placing of the work within its cultural context. I want to identify four distinct moments or aspects of interpretation, linking each aspect to Chris's meditation, which for this purpose I shall take to be representative of children's work as a whole.

Interpretation begins with the identification of the teacher with the work. The teacher becomes the reader, whose responsibility is to live within the work as if performing a score. So in reading Chris's meditation our first task is to share his original vision, making it visible to ourselves in memory or imagination; to follow the movement of his thought from moment to moment and word to word; to grasp the force of individual words and images, words, for example, such as "analyze" or "awake"; to sense the rhythm, speed, and dynamics of his language; to become, in thought, the new kid, feeling his confusion for ourselves. It is only by living within the work that we come to understand how a work such as New Kid represents the child's developing imagination.

Next comes commentary, the exposition of the work, as we draw out its meaning by more closely examining its thought and its language. It is commentary that leads us to recognize in the ending of New Kid not so much a recapitulation of the opening as its reconstruction in the light of the vision to which the opening words have given rise. It is by way of commentary that we read in the image of the "sea when it's awake" the troubled mind of the lonely outsider. It is commentary that helps us to define the work's underlying argument and uncover its "self-sufficient form." Commentary is not to be understood simply as an unmasking of the author's "deliberate intent." Intention does not exhaust the work's meaning; indeed it is tempting to suggest that the work knows more than its author intends (Woods, 2005). More precisely, it is the work itself that extends and advances its author's knowledge, just as it enlarges its reader's knowledge. This excess of the knowledge expressed within the work over the author's declared or implicit intention is what makes a work such as New Kid so valuable in education, whether for children or their teachers. In particular, it is this excess which governs the reader's response to the writer's work.

Critical response is the third aspect of interpretation to which I want to draw attention. For a pedagogy of the imagination it is the pivotal moment. Critical response has nothing to do with analysis as Chris portrays it in his meditation, that is 
to say the picking apart of the work. Its starting point is dialogue, or perhaps it would be better to call it conversation: the exchange of experience between teller and listener, reader and writer, teacher and pupil, and between both of them and the work itself. We relate the work to other works that we have read, to our sense of tradition, to our own lives and to our own imagination. Most readers of New Kid will immediately recall an image that echoes the blue pencil or the blue of the sea, while the sea itself will often call to mind a poem, a painting or a piece of music. The exchange of experience leads to questions between writer and reader, as when Chris was asked about the significance of the colour blue at the start of his meditation, and the questions, in their turn, give rise to a discussion of inconsistencies, gaps, puzzles, doubts, doubts for example, about the lack of punctuation or the purpose of the repetition of the opening words, or the significance of the sea being said to be "awake." A critical response has its dangers, to which Calvino's proposal draws immediate attention. At one extreme, critical response may only serve to suffocate a young writer's imagination while at the other extreme, an overindulgent response may leave the writer a prey to the ephemeral confusion of a daydream. Not least among a teacher's skills is the ability to avoid the danger without curtailing the conversation.

The purpose of a critical response is to help both writer and reader to become more aware of their imaginative goals and of the means to achieve them, that is to say to increase their self-consciousness, and it is this growing self-consciousness that conditions the fourth aspect of interpretation which looks to the future. What does a work such as New Kid tell us about the present imaginative interests of its author and what are the next steps that we might help him to take? The breathlessness of the text, however effective in the present instance, might lead us to discuss with Chris the value and purpose of punctuation and the way it will enlarge his formal opportunities. The metaphorical use which he makes of the sea will suggest to us the poetry which might engage his interest, not simply The Rime of the Ancient Mariner, but also folk tales such as the many sea stories among Calvino's (1980) own collection of Italian Folk Tales, which would lead his imagination into any number of new directions. The understanding of a young child's predicament displayed in his meditation might suggest a research project into other children's memories of their first day at school. It would surely encourage us to explore the problems of the newcomer further with Chris and his classmates, in drama, dance and narrative, as well as in classroom discussion. The teacher's responsibility is to take note of how the one work fits into the pattern of the child's work as a whole, to observe the direction of the child's thought, to reflect on the knowledge displayed within the work and to make connections to other aspects of the child's course of study and to the work of other students in the class. 
I may have made it appear that interpretation is a matter for the teacher and each child individually. Calvino's insistence that the pedagogy of the imagination is something which we can only practice upon ourselves tempts us to stress the privacy of the task. But this would be a mistake. Education is a collaborative enterprise and the success of a pedagogy of the imagination, within the common school, depends on reconstructing the classroom as a collective workshop, that is to say a community of students and teachers, jointly engaged on exploring the world through the critical practice of the various arts and sciences. Within the workshop, amid all the thinking and making, interpretation is a fundamental skill, not just for teachers, but equally for students. It is the way in which they come to share each others' insights, and respond with critical sympathy, the way in which they learn to read as imaginatively as they write. It is the way in which creative writers learn to become their own critical readers. Interpretation is necessarily circular, returning again and again to the work under review, though at different levels of understanding, and in Chris's classroom it was within the circle of children, sitting on the carpet with their teacher, that the work of interpretation would usually begin, as children read their work aloud to the rest of the class and the class responded with questions, comments, appreciations and tales of their own.

The educational value of interpretation is determined by the way in which it is documented. To document the work of a class of children is to tell the story of learning, and in so doing to answer the claims of accountability. A great variety of means may be brought together in the telling: the individual or collective works themselves, drafts of works in progress, written or taped notes and reflections by children and teachers, plans and projects, photographs and videos, sketch books and journals. In part, these documents form a record of the class's achievement, demonstrating to parents, school governors, local authorities, as well as to the children themselves and their teachers, the growth of the children's knowledge and the significance of that knowledge, not just for themselves, but for the world beyond the classroom, the cultural world in which the children are growing up. To exhibit children's work, in booklets and portfolios, exhibitions and displays, inside and outside the school, is to acknowledge its cultural value as well as to account for its success in terms of the children's advancing knowledge. But documentation is also essential to the process of learning itself. It is by observing, describing and interpreting their own work as it progresses from day to day that children become conscious of how to control their inner vision in ways that echo Calvino's account of his own procedure as a writer. Interpretation is thus the key to learning. 
The best example of documentation I know is to be found in the series of booklets published by the Municipal Infant Toddler Centres and Preschools of Reggio Emilia in Italy under the title The Unheard Voices of Children. In these extraordinary works the conversation, drawing and writing of very young children is juxtaposed with their teachers' comments and reflections in accounts of classroom projects devoted to subjects such as the nature of shadows, the problems of measurement, the workings of fountains, the study of children's rights. In the published report of the collaborative research project undertaken by Harvard University's Project Zero and the staff of Reggio's pre-schools, Carla Rinaldi (2001) sums up the purpose of documentation as follows: "Documentation, therefore, is seen as visible listening, as the construction of traces (through notes, slides, videos and so on) that not only testify to the children's learning paths and processes, but also make them possible because they are visible" (p. 83). The world of Calvino's great essay seems suddenly very close.

What, then, of assessment? What part does judgment play in a pedagogy of the imagination? In a chapter on "Criticism and Perception", in his book Art as Experience, John Dewey (1934) distinguishes between two kinds of judgment: the legalistic and the aesthetic. Legalistic judgment aims at delivering a verdict while aesthetic judgment Dewey defines as "an act of controlled inquiry." Legalistic judgment finds no place for the claims of the aesthetic."Criticism is thought of as if its business were not explication of the content of an object as to substance and form, but a process of acquittal or condemnation on the basis of merits or demerits" (p. 299). By contrast, within the sphere of the aesthetic,

the critic's office is to further [the] work performed by the object of art. Obtrusion of his own approvals and condemnations, appraisals and ratings, is a sign of failure to apprehend and perform the function of becoming a factor in the development of sincere personal experience. We lay hold of the full import of a work of art only as we go through in our own vital processes the processes the artist went through in producing the work (p. 325)

What Dewey says of works of art can be extended to the imagination as a whole. Within the realm of the imagination, interpretation and judgment are identical. "Explication of the content of an object as to substance and form" is precisely what interpretation entails. It is a central implication of interpretation that legalistic judgment is suspended in the interests of critical scrutiny. The teacher's task, or rather the reader's task, whether teacher or pupil, is not to assign the work a score but to inquire into its significance. That means, as we have seen, to bring the work to life in the act of reading, to elaborate its meaning, to challenge its confusions and respond 
to its insights, and to place it within the context of the child's and the class's developing culture. To describe and interpret work in this way is to value it. By the time evaluation is complete the urge to score the work for the most part disappears or comes to seem irrelevant.

Within a pedagogy of imagination criticism is formative rather than definitive. By submitting children's works to critical scrutiny, it aims both to recognize children's achievement and to advance their understanding. Its means are not the test and the score but the archive and the commentary. In this, as in so much else, the pedagogy of the imagination is at odds with the prevailing educational orthodoxy on both sides of the Atlantic. The improvisatory methods and unpredictable results, to which Calvino draws attention, are incompatible with a heavily prescribed curriculum. The language of targets, levels, standards, high stakes, is, at best, unimaginative. Above all, the innovative culture of the classroom is denied or belittled. Education becomes seen as a preparation for culture rather than a distinctive expression of culture. But I would not wish to end on a negative note. Better to reaffirm the imagination's credentials.

There is a passage in one of John Keats's letters (to his friend J.H. Reynolds) which seems to me to express perfectly the ultimate value and purpose of a pedagogy of the imagination.

Many have original Minds who do not think it - they are led away by Custom - Now it appears to me that almost any Man may like the Spider spin from his own inwards his own airy Citadel — the points of leaves and twigs on which the Spider begins her work are few and she fills the Air with such a beautiful circuiting: man should be content with as few points to tip with the fine Web of his Soul and weave a tapestry empyrean - full of Symbols for his spiritual eye, of softness for his spiritual touch, of space for his wandering of distinctness for his Luxury - But the Minds of Mortals are so different and bent on such diverse Journeys that it may at first appear impossible for any common taste and fellowship to exist between two or three under these suppositions - It is however quite the contrary - Minds would leave each other in contrary directions, traverse each other in Numberless points, and all at last greet each other at the Journey's end a old Man and a child would talk together and the old Man be led on his Path, and the child left thinking - Man should not dispute or assert but whisper results to his neighbour, and thus by every germ of Spirit sucking the Sap from mould ethereal every human might become great, and Humanity instead of being a wide heath of Furse and Briarrs with here and 
there a remote Oak or Pine, would become a grand democracy of Forest Trees." (Keats, p. 66)

John Dewey quotes from this passage, at the end of Art as Experience, to define "the way in which poetry acts" (p. 347). It is not in any way accidental that it should also be as fine a way as any to define both the method and aim of a pedagogy of the imagination and to assert its democratic credentials.

\section{References}

Armstrong, M. (2006). Children writing stories. Maidenhead, Open University Press.

Bakhtin, M.M. (1986). Speech genres and other late essays, Austin, University of Texas.

Calvino, I. (1980). Italian folk tales. New York: Harcourt Brace \& Company.

Calvino, I. (1988). Six memos for the next millennium. Cambridge, MA: Harvard University Press.

Coleridge, S.T. (1797-1798/1978). The portable Coleridge (ed. I.A. Richards). London: Viking Penguin Inc.

Dewey, J. (1934). Art as experience, New York: Minton Balch \& Company.

Hawkins, D. (1974). The informed vision, New York: Agathon Press.
James, H. (1934). The art of the novel. New York: Charles Scribner's Sons.

Keats, J. (1970). Letters of John Keats. (ed. Robert Gittings). Oxford: Oxford University Press.

The New Shorter Oxford English Dictionary (1993). Oxford: Clarendon Press.

Rinaldi, C. in Project Zero \& Reggio Children (2001). Making learning visible, Reggio Emilia, Reggio Children.

Tolstoy, L.N. (1982). Tolstoy on education. London: Athlone Press.

Wood, M. (2005). Literature and the taste of knowledge. Cambridge: Cambridge University Press.

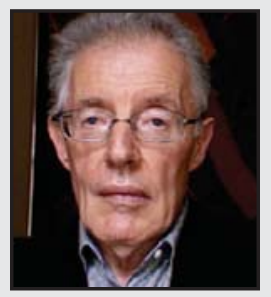

Michael Armstrong was for twenty years headteacher of Harwell Primary School in Oxfordshire, England. He is a visiting professor at the Bread Loaf School of English at Middlebury College, Vermont, where he teaches every summer in the Bread Loaf graduate program. He has written numerous essays on education and is the author of two books, Closely Observed Children (London, Writers and Readers, 1981) and Children Writing Stories, (Maidenhead, Open University Press, 2006). 